\title{
Cambio climático y crisis de sobrevivencia como amenaza global
}

Jorge Flores Silva ${ }^{1}$

\section{RESUMEN}

El objetivo de la presente investigación es explicar la crisis ecológica como resultado del crecimiento sin límite y el consumo desmedido que pone en peligro la naturaleza y al mismo ser humano que depende de ella. La metodología utilizada es el método descriptivo, intuitivo y el método dialéctico. La investigación combina el carácter cualitativo con elementos cuantitativos en campos específicos relacionados con la deforestación. Su enfoque es crítico respecto a posturas y líneas de pensamiento en torno a la crisis ecológica como amenaza global. Los resultados alcanzados son: i) la crisis como efecto del cambio climático es manifestación de la crisis del modelo de acumulación, basado en el crecimiento y consumo desmedido sin guardar la racionalidad en la explotación de los recursos. ii) las grandes empresas son las principales responsables de la contaminación ambiental y del desplazamiento de comunidades rurales que han sufrido la desarticulación de la agricultura campesina e indígena, al sustituirla por la agricultura industrial del monocultivo y la gran plantación. iii) la deforestación, los incendios forestales, la tala ilegal de árboles, el gorgojo descortezador han ocasionado disminución de los ciclos pluviales, causando erosión de suelos, cambio en los ciclos productivos, secado las fuentes de agua y modificado los ciclos que regulan el clima e incide en la perdida de la biodiversidad zoológica y vegetal. iv) Más de 440 mil hectáreas han sido afectadas por el gorgojo descortezador en apenas siete meses lo que significa alrededor de 86 millones, 240 mil pinos, a un promedio de 196 pinos por hectárea según parámetros del Instituto de Conservación Forestal.

Palabras claves: racionalidad, sostenibilidad, transnacionales, transgénicos, agroquímicos.

\footnotetext{
${ }^{1}$ Profesor investigador del Instituto de Investigaciones Económicas y Sociales (IIES-UNAH), Facultad de Ciencias Económicas, UNAH: jaflosi@hotmail.com
} 


\section{ABSTRACT}

The aim of this research is to explain the ecological crisis as a result of unlimited growth and wasteful consumption that threatens nature and the same human being depends on it. The methodology used is descriptive intuitive and dialectical method. The research combines qualitative with quantitative elements in specific fields related to deforestation. Its approach is critical of positions and lines of thought about the ecological crisis as a global threat. The results achieved are: i) the crisis as an effect of climate change as a manifestation of the crisis of accumulation model based on growth and wasteful consumption without saving the rational exploitation of resources. ii) large companies are primarily responsible for environmental pollution and displacement of rural communities that have suffered the dismantling of peasant and indigenous agriculture, industrial agriculture replace monoculture and large plantation. iii) deforestation, forest fires, illegal felling of trees, bark beetles have caused decrease in rainfall cycles, causing soil erosion, change in production cycles, drying water sources and modification in climate regulation cycles and the loss of zoological and plant biodiversity. iv) Over 440,000 hectares have been affected by bark beetle in just seven months which means about 86 million, 240 thousand pine trees, an average of 196 pine trees per hectare according to parameters of the Forest Conservation Institute.

Keywords: rationality, sustainability, transnational, transgenics, agrochemicals 


\section{INTRODUCCIÓN}

El problema del cambio climático ha tomado importancia en el debate mundial y forma parte de la agenda internacional de los gobiernos y organismos multilaterales y supranacionales; pero, se ha avanzado en ideas, mas no en realizaciones prácticas. Por eso, se vuelve necesario pasar del discurso a la acción para garantizar el cuidado del planeta y la existencia del ser humano evitando la explotación irracional y desmedida de los recursos naturales guardando la racionalidad.

Muchos organismos internacionales, particularmente el Fondo Mundial para la Naturaleza y la Unión Mundial para la Naturaleza, no hace mucho tiempo afirmaban que cerca del $10 \%$ de toda especie de árboles podrían desaparecer, es decir, unas 10,000 especies de árboles conocidas científicamente. A nivel mundial, se pierden cerca de once millones de hectáreas de bosque por año, casi el equivalente a la superficie territorial de Honduras, cuyo territorio está configurado por 11.5 millones de hectáreas. El problema es doblemente grave porque apenas la cuarta parte de las especies en extinción están siendo protegidas.

El crecimiento sin límite y el consumo desmedido están poniendo en peligro el planeta $y$, por consiguiente, al mismo ser humano que depende de la naturaleza y sus recursos. Se está ante una crisis que si crece genera problemas ecológicos y si no se crece genera crisis social, ya que no son dos crisis separadas, una ambiental y otra social, sino una sola y compleja crisis socio-ambiental (Papa Francisco, 2015).

Todo es resultado de la acción humana y también está en nuestras manos la solución, pero mientras no se tome conciencia que si se destruye la naturaleza también nos autodestruimos, los esfuerzos realizados quedarán en simples enunciados y declaraciones. Es tiempo de tomar medidas urgentes para salvar el planeta, así, orientar la economía en función de la reproducción de la naturaleza para la reproducción de la vida es el reto insoslayable. Desafortunadamente, en una economía de acumulación se tiende a acabar con todo porque se parte de la lógica de que todo es reemplazable, este es el enfoque y visión de la economía ambiental, de modo que ante esta realidad hay que contraponer la economía ecológica que ve la realidad del planeta bajo otra perspectiva: hay que vivir en armonía con la naturaleza, cuidándola, rehabilitándola y conservándola.

Si la economía se basa en función de los bienes de la naturaleza, porque es de la naturaleza de donde se obtiene la materia prima para producir los bienes o productos, 
también la economía debe dictar las líneas para su reproducción y cuidado, evitando que la tierra se convierta en un botadero que no le permite ser suficiente para la regeneración de los desechos de manera natural.

Al no haber cultura ecológica, tampoco se le da importancia a la clasificación de desechos para convertirlos en tierra fértil o abono natural para los suelos. Muchos empaques, bolsas o envases, no se regeneran fácilmente, más bien producen tóxicos nocivos a la salud de los seres vivos, plantas, seres humanos y animales. Este envenenamiento ocurre por la contaminación de las aguas, los suelos y el medioambiente en su conjunto. El plástico, la lata, el vidrio lleva mucho tiempo para su regeneración, no se deshacen fácilmente, contrario a lo que sucede con la materia orgánica, como los desperdicios hortícolas, cáscaras de las frutas, hojarasca y madera, etc. En consecuencia, las quebradas, ríos, cunetas, canales de distribución de aguas y tragantes, no deben ser tiradero de basura por el efecto tóxico nocivo que implica y por ser causa de inundaciones que afectan a las comunidades, principalmente a las más vulnerables.

\section{Objetivos}

1. Explicar la crisis ecológica como resultado del crecimiento sin límite y el consumo desmedido que pone en peligro la naturaleza y al mismo ser humano que depende de ella, debido a un modelo de acumulación que opera sobre la base de la utilidad y la máxima ganancia, donde a todo se pone precio y se mercantiliza, sin guardar la racionalidad en la explotación y el uso de los recursos naturales.

2. Describir el problema relacionado con el uso de los transgénicos y sus consecuencias nocivas para los seres vivos, en virtud de sus efectos dañinos en la salud de las personas, la flora y los animales y de todo ser vivo como consecuencia del crecimiento acelerado de la agricultura industrial que busca comercialización rápida para generar riqueza acelerada.

3. Destacar el papel de la tecnología en el problema del cambio climático, la cual por la misma lógica del modelo que se impulsa, no se ha utilizado para resolver los problemas de la pobreza, ni para conservar y rehabilitar la naturaleza, sino para socavarla sin caer en cuenta sobre la conciencia del límite, porque la naturaleza tiene límite y puede ser destruida. 


\section{MÉTODO}

La investigación tiene un enfoque crítico con carácter cualitativo, combinando elementos cuantitativos en campos específicos relacionados con la problemática de la deforestación y su efecto negativo en el medioambiente.

Hubo preguntas de investigación de manera expresa a técnicos del Instituto de Conservación Forestal y de manera implícita en la revisión bibliográfica para cotejar posturas y líneas de pensamiento en torno a la crisis ecológica como amenaza global. Se aprovechó también el método descriptivo, el método intuitivo y el método dialéctico.

\section{La deforestación}

Los bosques y áreas selváticas pulmones de la humanidad

El crecimiento sin límite y las medidas cortoplacistas del utilitarismo para la rentabilidad inmediata sin importar las generaciones venideras, han dado pie para el acelerado agotamiento de las reservas naturales y la emisión de gases tóxicos de efecto invernadero, que han resultado en un deterioro ambiental y en la disminución de la calidad de vida de la población.

No se puede desestimar en el análisis lo que se refiere a la concentración de la propiedad agraria y el desorden territorial en donde convive la gran propiedad, el acaparamiento de territorios y las cuencas hidrográficas con el mini y microfundio. El antagonismo entre la gran propiedad y la pequeña propiedad agraria no es independiente del alto grado de concentración como problema estructural, que da lugar al mal uso de la tierra en donde se realizan prácticas agrícolas que no van en armonía con las características agroecológicas de las regiones.

Estas malas prácticas ocasionan erosión, desertización y destrucción de los suelos, ejemplo de ello es la agricultura migratoria desarrollada por quienes no tienen acceso a la tierra plana y fértil de los valles, en virtud de que estos se encuentran acaparados sin cumplir una verdadera función social. La explotación ganadera de manera extensiva $o$ en el peor de los casos el mantener la tierra inculta u ociosa, no es independiente para que grandes contingentes de campesinos emigren hacia las áreas selváticas o boscosas.

Como el maíz, los frijoles, el arroz y otros cultivos anuales o transitorios necesitan de 
la luz solar para desarrollarse, entonces se acude al descombro sin comprender bien por necesidad o por falta de formación, que con el corte o tala de los bosques se destruye el medioambiente, la biodiversidad zoológica, la flora y las fuentes de agua tan necesarios para la vida.

En esta problemática juega un papel importante la educación o la capacitación, ya que se puede concienciar a los cultivadores rurales para que orienten sus actividades agrícolas hacia otros rubros, que vivan en armonía con el bosque y que pueden obtener iguales o mejores rendimientos sin destruir el suelo, porque estarían en consonancia con las características agronómicas de la tierra, dedicándose por ejemplo a la explotación de frutos de altura, café, cultivo de flores, cardamomo y algunos cítricos, etc.

Desde luego, la explotación irracional de la tierra, incluyendo la deforestación, está relacionada con los patrones de apropiación de la propiedad, también es cierto que no es independiente del crecimiento desordenado de la población que presiona sobre un mismo espacio físico fijo. Es obvio que la población crece, pero la tierra no; la población rural presiona por el mismo espacio fijo y si no hay reordenamiento territorial genera conflictos agrarios.

También aumenta el microfundio, se incrementa la agricultura migratoria hacia el bosque, se desertifica y destruye o erosiona el suelo de manera acelerada y las consecuencias son funestas y ya las estamos experimentando. Se pierde la belleza de las montañas que atrae el turismo ecológico, se agudiza el problema de las precipitaciones pluviales, se secan las fuentes de agua y la temperatura es cada vez más agobiante.

Honduras no es la excepción de lo que ha pasado y pasa en África y América del Sur, que sufre la deforestación inmisericorde; estas regiones - sobre todo Brasil, Colombia, Venezuela, Perú y Ecuador- tienen las mayores reservas de bosque y agua, sin embargo, sufren la explotación irracional de sus recursos. Son estas regiones de bosque tropical las que constituyen el pulmón de la humanidad, pero, el capital transnacional privilegia el dominio del dinero y la máxima ganancia en oposición al bien común.

Este mismo cálculo de utilidad ha sido motivo de desplazamiento de las comunidades originarias que milenariamente han vivido en armonía con el medioambiente. La lucha de los indígenas y los campesinos no es una lucha egoísta, es una lucha por el bien de la humanidad, la población de las ciudades no terminan de intoxicarse gracias 
al cuidado de los bosques y las áreas selváticas que le dan los pueblos originarios. Países iguales o más pequeños desde el punto de vista territorial que Honduras, han tomado medidas de carácter ecológico desde hace muchos años y hoy gozan de un entorno agradable y diversidad biológica que les permite explotar el turismo ecológico o de montaña. Además, la variedad zoológica y vegetal la utilizan por su valor alimenticio y medicinal de manera sostenida

Sin embargo, en Honduras todavía no tomamos conciencia de la gravedad del problema del cambio climático y por lo mismo estamos sin definir una adecuada política de protección de los recursos naturales. Esto no significa no aprovecharlos, sino usarlos de manera racional, procurando la sostenibilidad en el tiempo. En el caso de los bosques se está ante un grave problema, no solo por los modos de vida y de consumo, sino por las prácticas agrícolas que a su vez están asociadas al grado de concentración agraria, la falta de adecuados planes de manejo que cuiden de no meter la sierra a los árboles jóvenes, a los semilleros y a los que todavía no tienen el diámetro adecuado. Sumado a los factores planteados, hoy en día se agudiza el problema de la deforestación, porque entre más altas sean las temperaturas, más proclives son los incendios que según el Instituto de Conservación Forestal (ICF), se han visto afectados cerca de cuarenta y ocho mil hectáreas $(48,000)$ de bosque solo entre el año 2015 y los primeros cuatro meses del año 2016; contabilizando solo en 2015 alrededor de 29,200 hectáreas. A esto hay que agregarle el daño ocasionado por el gorgojo descortezador del pino, que al momento de elaborar este estudio se cuantificaban cerca de cuatrocientos cuarenta mil hectáreas (440000 hectáreas) dañadas a nivel nacional, equivalente a ochenta y seis millones doscientos cuarenta mil pinos $(86,240,000)$, a un promedio de 196 pinos por ha según técnicos del ICF. Siendo los departamentos de Olancho, Francisco Morazán, Comayagua, Yoro y El Paraíso los más afectados por la plaga. Si seguimos a ese ritmo y no tomamos medidas urgentes en el cuidado de la naturaleza y sus recursos, estamos ante una amenaza para la sobrevivencia.

Todavía hay posibilidades de detener el problema, pero ello implica decisión política, porque toda acción económica afectará los intereses privados de unos y favorecerá al bien común 0 , al contrario, se afectará el bien común y se favorecerá al interés privado. Debido a esto siempre habrá fuerzas sociales que se oponen a ciertas medidas, en virtud de lo cual las medidas que se tomen siempre deben ir orientadas al bienestar colectivo sin dejar de pensar en las generaciones venideras. He allí una estrategia de desarrollo de largo plazo que tenga factibilidad económica, factibilidad técnica y viabilidad política: "La protección del medioambiente deberá constituir parte integrante del proceso de desarrollo y no podrá considerarse en forma aislada" 
(Declaración de Río sobre Medioambiente, 1992).

Lo importante en todo esto es tener conciencia de que el calentamiento es una realidad, que el agua es un bien común cada vez más escaso y que sin este preciado líquido no se puede vivir, de él dependemos los seres humanos y todo ser viviente, es parte de los procesos biológicos, es un componente vital de todo ser vivo, si pierde agua su organismo se deshidrata y se pasa del límite de sobrevivencia que puede llegar hasta la muerte.

Más de las dos terceras partes de la superficie terrestre están constituidas por agua, aproximadamente el $70 \%$, aparentemente es bastante y suficiente, sin embargo, toda esa agua no es la que necesitamos para la sobrevivencia, por lo menos hasta ahora, porque es agua que está en los mares que es salada; otra parte está en los polos y glaciares y solamente un porcentaje aproximado al $2.5 \%$ es agua dulce, que el ser humano necesita para vivir. Si hoy el petróleo es causa y efecto de muchos conflictos, que con frecuencia se utiliza como arma económica y política, en el futuro el agua puede ser factor de conflicto porque se están agotando las fuentes de reserva. Algunas transnacionales empiezan acaparar el agua para fines mercantiles, técnicas de extracción petrolera como el "fracking" que está contaminando el agua y desperdiciándola, algunas comunidades emprenden luchas porque sus aguas se están acaparando y los ríos están siendo desviados por empresas mineras.

Toda la problemática del medioambiente debe impulsar no solo el debate sobre la explotación y dominio del ser humano que con apoyo del progreso técnico somete y destruye el planeta, el único lugar común que tenemos para vivir. No podemos continuar haciendo con los recursos naturales lo que se nos ocurre de manera arbitraria para mantener la rentabilidad a costa de la tierra y la propia humanidad. Somos seres naturales y debemos sentirnos parte de la naturaleza, cuidándola y reproduciéndola también a partir del proceso de hacer ciencia y crear tecnología.

Cuidar la tierra también implica cuidarnos a nosotros mismos, de qué serviría cuidar la naturaleza si no fuera el ser humano su fin. Según Augusto Serrano (1997): "El desarrollo es humano o no es desarrollo, es de todos o no es desarrollo, lo contrario será un camino destructivo." El problema del cambio climático que amenaza la humanidad es un problema de profundo contenido cuando nos damos cuenta de que la naturaleza tiene límite y que puede ser socavada, todo tiene límite hasta el conocimiento y no digamos el espacio geográfico fijo, presionado por una población en constante crecimiento y bajo la mira de un progreso técnico que no siempre está al servicio de la humanidad. 
Hablar de la Tierra es hablar del medioambiente y, por consiguiente, del ser humano que la habita, que también tiene no solo una dimensión psicológica y espiritual, sino también material, pero que al mismo tiempo no solo es biología que nace, crece, se desarrolla y muere, sino que a diferencia de las demás creaturas tiene un carácter multidimensional o psicobiosocial. Garantizar la existencia del ser humano no debe ser a costa de explotar y destruir la naturaleza, debe ser parte de un proceso reproductivo de la misma naturaleza explotándola y rehabilitándola de manera que haya bienes y trabajo mientras estemos de paso por esta vida, que haya sostenibilidad en el tiempo y permita a las generaciones venideras vivir con dignidad.

Todo ello implica guardar la racionalidad a través de una economía para la vida. En tal sentido, el objetivo del proceso económico deber ser la vida, en oposición al utilitarismo o a la máxima ganancia, de esta forma el crecimiento económico deja de ser un fin en sí mismo y se constituye en un medio para alcanzar el desarrollo en función de la vida. "Si en ese proceso económico el objetivo es la máxima ganancia, entonces el crecimiento adquiere importancia, de tal suerte que la sostenibilidad no tiene una relación directa con la vida, más aun con la sostenibilidad de la vida humana, solo en aquellos aspectos que no afecten la máxima ganancia" (Hughes, 1998).

De tal suerte que los criterios para la lógica del cálculo y la utilidad resultan ser ilógicos e irracionales sin importar la sostenibilidad de la vida, porque lo que importa es la sostenibilidad del capital, la sostenibilidad fiscal y la sostenibilidad de las máximas ganancias. Los criterios giran en torno a que hay que producir lo que demanda el que tiene poder de compra, se produce lo que la gente quiere y las empresas producen lo que la gente que tiene acceso al ingreso demanda, porque la demanda efectiva se expresa monetariamente sin interesar las necesidades globales de la sociedad. Priva la "cultura de muerte" por sobre la vida. De ahí que a la gente se le categoriza de primera, segunda o tercera categoría, según sean sus capacidades de consumo y no solo de consumo como variable económica importante en el proceso de producción y distribución, sino capacidad de consumo desmedido o consumismo. Por eso el crecimiento y el dinero convertido en capital deja de ser un medio para dignificar la persona y se le concibe como un fin en sí mismo.

\section{La crisis ecológica}

En la era del poder del dinero en donde las transnacionales han asumido un papel protagónico como agentes de la economía globalizada, los medios opacan los fines. Priva lo virtual sobre lo real, en donde la economía financiera realiza sus transacciones con el poder de los títulos valor, las acciones, las letras de cambio, así se produce 
riqueza con la riqueza creada. La economía financiera deja de complementarse con la economía real para tomar preponderancia en un mundo globalizado que deja traslucir sus contradicciones. Porque si el propósito de la globalización es la libre movilidad de bienes, personas y capital, este fin solo se cumple con el capital que puede desplazarse por todo el mundo con gran facilidad, no así los trabajadores que corren el riesgo de las redadas y la deportación; los productos tampoco se movilizan con facilidad por las barreras arancelarias y fitosanitarias.

Esa es parte de la realidad que vive el mundo, crisis sobre crisis, siendo la más dramática la crisis ecológica porque está de por medio la sobrevivencia. Pero, esta no es independiente de la crisis ética, económica, social o, dicho de mejor forma, de la crisis socioambiental.

Con el afán de captar recursos y equilibrar balanza de pagos, sobre la base del equilibrio de la balanza comercial, se hacen evaluaciones o valoraciones económicas de corto plazo: estimulando la agricultura industrial para el mercado externo por sobre la agricultura campesina e indígena, de esta forma se pone en riesgo la seguridad alimentaria. Al no estimular la agricultura para el mercado interno, el agro cae en el rezago y pierde competitividad contribuyendo de esta forma a que los pequeños cultivadores vendan sus pequeñas parcelas, las abandonen y emigren a las ciudades 0 a otras latitudes fuera de la frontera patria.

Todo esto se ha convertido en un mecanismo de fácil acaparamiento de tierras por los que inciden en el poder o por los que tienen capacidad de comprar las tierras abandonadas o que los pequeños propietarios por no hacerlas producir debido a la ausencia de servicios de apoyo productivo optan por venderlas. El mercado de tierras que se ha estimulado en Honduras con la Ley de Modernización Agrícola en oposición a la Ley de Reforma Agraria, solo ocurre entre los que tienen dinero. El campesino pobre no compra tierras, más bien las vende por no poder cultivarlas o porque sus rendimientos resultan ser nulos o muy bajos por las razones expuestas, entonces quien compra tierras es el rico. De esta forma, esas evaluaciones cortoplacistas solo visualizan el comercio exterior, la apertura de mercados para los rubros de exportación de palma africana, banano, caña de azúcar, tabaco, madera, etc. En el caso de la madera que ocupa un lugar preponderante en la exportación, se argumenta que genera divisas, que favorece la balanza comercial, pero no se reflexiona sobre el costo ambiental que ello implica, sobre todo en esta etapa de crisis ecológica por los desastres que ha causado y está causando el gorgojo descortezador; los incendios forestales que cada año van en ascenso, la tala ilegal de madera, la explotación sin planes de manejo y raleo y el aprovechamiento indebido con la excusa del gorgojo 
para justificar el corte ilegal de madera.

El camino destructivo por el afán del dinero fácil y rápido que afecta y excluye a los más pobres de las comunidades originarias, terminará por destruirnos a todos si no cambiamos los estilos y modos de vida y consumo. Pero, sobre todo, sino se cuestiona la racionalidad del modelo que se impulsa que tiene una lógica más de muerte que de vida, estamos ante la necesidad de una reforma objetiva desde el punto de vista económico y una reforma o intervención subjetiva desde la óptica de la educación. La lucha no solo es económica para alcanzar bienestar material, también es imprescindible una lucha cultural, una lucha educativa para incluir en el currículo, columna vertebral del sistema de educación, el cuidado de los recursos naturales como eje transversal para todos los niveles del proceso enseñanza-aprendizaje, tanto del nivel preescolar, primario, secundario y terciario, sin descuidar la educación no formal en todos los sectores.

Solo así se podrá ir formando una conciencia ecológica para el cuidado de la tierra y sus recursos, los cuales tienen límite y pueden ser destruidos. Los seres humanos necesitamos no solo sobrevivir, sino vivir y vivir bien, ello significa optar por la vida del ser humano y de las especies animal y vegetal, negando al mismo tiempo el poder del dinero, lo que tampoco significa parar el progreso y desarrollo de los pueblos. Si los recursos naturales son indispensables para que el ser humano actúe sobre ellos en su transformación que garantice trabajo y existencia de bienes para satisfacer necesidades, entonces la acción humana debe procurar la existencia de estos recursos de manera sostenible, aprovechándolos con inteligencia y de manera racional.

Únicamente de esta forma podremos tener acceso a los bienes materiales, a los bienes sociales y a los bienes culturales. Si optamos por la vida, el crecimiento ya no es un fin, sino un medio en función del bien común. Este es el enfoque crítico que debe plantearse en los distintos espacios que nos corresponde: la academia, el gobierno, los organismos nacionales e internacionales, como expresión de la crisis de reproducción para la vida. No debe dejarse solos a los campesinos, ni mucho menos dejar solos en esta responsabilidad socioambiental a los pueblos indígenas porque su lucha atañe a todos. Esta lucha no es una quimera ecológica, los indicadores medioambientales y las cifras de destrucción de la flora y fauna a nivel mundial y nacional dan cuenta de que los organismos son más que preocupantes, entonces, la responsabilidad es o cuidamos y distribuimos bien los recursos o nos morimos todos. "Los paisajes, los bosques, el hábitat de los pueblos colonizados, se alteraron por la explotación de los recursos naturales. Pocas voces se elevaron para denunciar tales situaciones, porque era ese el precio del progreso. Fue necesario que la situación se 
deteriorara al punto de afectar los intereses económicos y la calidad de vida de todas las capas sociales, incluidos los grupos socialmente dominantes, para que la destrucción ecológica se pusiera sobre el tapete" (Houtart, 2011).

Aun así, la creencia en un desarrollo y progreso lineal e infinito, que prevaleció en la era de la ilustración, todavía persiste en algunos sectores, tal vez no en la retórica, pero si en la acción práctica y más todavía, creer que el desarrollo solo puede darse sobre la base de la destrucción de la naturaleza, sin considerar sus límites, por eso se tiende a acabar con todo, bajo el supuesto de una economía ambientalista que considera que todo es reemplazable. De ahí la creación del capital artificial para continuar explotando el capital natural. Así se planea la obsolescencia temprana de los bienes, cuya vida útil cada vez se reduce más y con ello también se disminuye la vida del ser humano que depende de la naturaleza para la obtención de los recursos naturales que necesita en la producción de tales bienes.

Sin embargo, la lógica de acumulación hace caso omiso de la tragedia y amenaza para la humanidad y todo ser viviente, al grado de crear presión para restar importancia a tal amenaza: "El comité de información sobre el medio ambiente... afirmaba que el calentamiento climático era una hipótesis teórica y no una realidad" (Houtart, 2011). Los acuerdos de las cumbres sobre la Tierra y el medioambiente quedan en simples considerandos en virtud de la política económica excluyente que se aplica por la mayoría de los gobiernos, convencidos por los organismos multilaterales de financiamiento para que apliquen tales medidas que solo pobreza y desplazamiento han generado, al tal grado que hoy en día un alto porcentaje de la población mundial, principalmente de África y América Latina, vive de ayuda humanitaria.

Son los que tienen influencia en los poderes estatales los que terminan decidiendo y controlando las reglas del juego, la producción y los precios. Entre estos protagonistas principales están las transnacionales, cuyo afán por acaparar tierras para el monocultivo, como la palma africana, ha ocasionado desplazamiento de comunidades enteras. De esta forma, los antiguos propietarios terminan enrolándose como jornaleros de las grandes empresas con salarios de subsistencia. Cualquiera que no haga un mayor análisis podrá decir: para qué vendieron sus tierras estos campesinos, si ellos así lo quisieron ahora que no se quejen.

Sin embargo, no se dan cuenta que detrás de este acaparamiento y desplazamiento hay toda una labor de convencimiento que linda con el engaño, diciendo que se garantizará seguridad alimentaria, que la palma africana y otros cultivos permanentes del monocultivo son ecológicos, que tendrán garantizado empleo, buenos salarios y 
otras bondades; pero que a fin de cuentas nada de todo eso resulta cierto y la experiencia dice que solo ha traído desempleo, desplazamiento, hambre, contaminación de aguas o agotamiento de las fuentes y hasta la muerte.

Este acaparamiento de tierras también pasa por campañas de convencimiento a los gobiernos para que den facilidades y adopten medidas de apertura de mercados, incrementen las exportaciones y otras políticas de ajuste que terminan volviéndolos cómplices de la muerte lenta y desaparecimiento de los pueblos originarios. Este desplazamiento no llega hasta allí, también ha provocado escasez de alimentos y alza de precios, porque grandes extensiones de selva que eran cultivados con diversidad de cultivos alimenticios que vivían en armonía con el bosque para no descombrarlos, así como los valles fértiles y de tierra plana donde se explotaban rubros para la alimentación, hoy están siendo cultivados de palma africana para satisfacer la demanda de los agrocombustibles de países ricos. En todo esto los únicos favorecidos con el monocultivo de la agricultura industrial son las transnacionales y las grandes empresas nacionales. Dejando a los países y a la población sin los bosques 0 selvas, sin agua, desplazamiento, destrucción, hambre y muerte.

Otro fenómeno de la transnacionalización que está ocurriendo en muchos países es que cuando los gobiernos toman medidas contra los excesos de estas grandes empresas por no cumplir las regulaciones internas del país donde operan, porque suspenden concesiones por contratos leoninos o porque están contaminando las aguas y el ambiente que causan efectos lesivos a la salud de las poblaciones o comunidades aledañas donde operan, estas empresas responden con una demanda ante los organismos o tribunales internacionales. Tales organismos con una óptica distorsionada de lo que implica el desarrollo sostenible, generalmente dictan sentencia a favor de las transnacionales, obligando a que los pueblos terminen pagando sumas millonarias por indemnización a estas empresas. Con el agravante de que se les paga aún después de comprobarse que han contaminado el ambiente y las aguas donde han operado.

Estos flujos millonarios por concepto de indemnizaciones quitan recursos a los programas sociales hacia donde debían orientarse para mejorar las condiciones de vida de la población. De modo que esta situación al fin de cuentas más bien genera inequidad y desigualdad, que en buen castellano no puede llamarse de otro modo, sino que injusticia social. Así, la transnacionalización no solo genera acaparamiento de territorios, desplazamiento de la población, acaparamiento, desvío y contaminación de las aguas, intoxicación y enfermedades, sino que da lugar en forma acelerada al desempleo, carestía de alimentos y alza de precios de aquellos productos que 
antes se producían localmente y que ahora hay que importarlos. Esto invita a reflexionar de manera crítica ante una crisis que se transforma en crisis planetaria como resultado, de una racionalidad que produce riqueza destruyendo las fuentes que generan riqueza, según el pensamiento reflejado en el conversatorio académico con el Profesor F. Hinkelammer.

\section{Agua, líquido vital: tecnología como medio no como fin}

La situación se vuelve más grave cuando la tecnología se absolutiza y no se usa al servicio del ser humano. Esto no significa que hay que subestimar la tecnología, sino llamar la atención para utilizarla como medio y no como fin en sí misma. La tecnología debe aprovecharse no para destruir, sino para construir países fuertes, usándola para combatir la pobreza, cuidar, rehabilitar y conservar los recursos naturales, en fin, poner la tecnología al servicio de la gente, donde la persona no esté supeditada ni al dinero, ni a la tecnología, sino que la tecnología y el dinero dependan de la persona. La tecnología del "fracking" para extraer petróleo ha venido a afectar más el medioambiente, esta técnica además de que requiere mucha agua también la contamina. Es la técnica que en los últimos años ha utilizado principalmente EE.UU., llamada también técnica de la ruptura hidráulica, perjudicial para las personas, animales y las plantas, según estudios científicos hechos en los mismos Estados Unidos.

Estos llamados de alerta de los científicos no importa cuando se trata de hacer la guerra utilizando como arma económica y política los recursos naturales, como es el caso del petróleo que al incrementarse su oferta tienden a caer los precios, de esta manera afecta a los países que dependen de este rubro para incrementar sus ingresos y equilibrar sus presupuestos. Pero, favorece a los países importadores de este producto, al reducir la factura petrolera que puede favorecer la economía siempre que no se incremente el derroche como pretexto por la baja de precios. De todas maneras, sea que perjudique o favorezca a los países la fluctuación de precios de petróleo, aumentando o disminuyendo la oferta y sus incidencia en la demanda, siempre se estará en la ruta de la contaminación, el uso de combustible o energía fósil y todo aquello que emita un exceso de dióxido de carbono y gas metano.

La situación del cambio climático que ha dado lugar al fenómeno de El Niño o La Niña, provoca en ciertas épocas del año y en algunas regiones la sequía o las inundaciones, ambos fenómenos perjudiciales para la población y la producción agrícola. Todo ser vivo necesita del agua y los alimentos para sobrevivir, pero el cambio climático generado por la acción irresponsable del ser humano ha venido a cambiar los ciclos pluviales, los ciclos productivos y los ciclos para mantener el equilibro natural. 
Las preguntas que saltan a la vista son: el problema es del calentamiento global o el problema es resultado del modelo y modo de hacer economía; es problema de la naturaleza o es problema de la economía que se impulsa. La respuesta puede ser obvia, pero implica decisión política y voluntad nacional para renunciar a la máxima ganancia y optar por la vida, que sería la alternativa. No se podrá sobrevivir si no optamos por una economía para la vida, pues no se trata solo de cambiar la energía fósil por la energía renovable, ni de solo producir agrocombustibles provenientes de la palma africana o la caña de azúcar u otras plantas, porque esto también podría ser catastrófico, como ya está ocurriendo dado que ese tipo de monocultivos está ocupando las tierras que antes eran utilizadas para producir alimentos.

También se están deforestando grandes áreas y con ello causando estragos a la biodiversidad, por la producción de palma. Se estaría saliendo de un problema para pasar a otro más grave. El reto está en buscar una alternativa sostenible partiendo del cuestionamiento del modelo de acumulación, pero las soluciones a partir de poner en duda la lógica del modelo sería a largo plazo. Actualmente se pueden apoyar más los esfuerzos por mejorar las prácticas agrícolas, que incluye la diversificación sin caer en la dependencia de un solo cultivo que afecta la seguridad alimentaria y desplaza a las comunidades originarias. Otra solución puede ser lograr la eficiencia en el uso de energía más limpia para el entorno que puede regenerarse de manera natural como la producida por el viento, la luz solar y las corrientes marinas. Estos recursos, además de limpios, también se encuentran en la naturaleza y no producen emisiones de efecto invernadero.

Otro problema grave es el del agua, que está asociado a las transnacionalización de los recursos estratégicos, a la deforestación, el monocultivo y las actividades extractivas principalmente de algunos metales preciosos como el oro. Con razón hoy se habla de que en el futuro las guerras ya no van a ser por el control de las reservas de petróleo, sino por el control del agua que empieza a privatizarse, dejando por fuera la visión que siempre hemos tenido de que el agua es un bien común y un derecho humano. Todo lo relacionado con lo ecológico está estrechamente asociado con el agua. El agua es vida, sin agua no se pueden producir alimentos y, por tanto, cuando disminuyen los caudales o se contaminan las fuentes, se pone en riesgo la vida y la seguridad alimentaria para todo ser vivo.

"La causa principal de la contaminación del agua es la descarga directa de desechos domésticos e industriales no procesados en cuerpos de agua superficial. Ello contamina no solo los cuerpos de agua, sino también los acuíferos de agua subterránea adyacentes. Con la expansión de la industria, la minería y el uso de agroquímicos, los 
ríos y acuíferos se contaminan con sólidos orgánicos, químicos tóxicos y metales pesados" (informe GEO-P.N.U.M.A. citado por R.H. May, 2004)

Sin embargo, las Naciones Unidas no tiene capacidad decisiva sobre todo ante los países ricos que son los que más contaminan y sus pronunciamientos se quedan en simples enunciados o declaraciones, queda entonces hacer algo para revertir esta amenaza que se vuelve global. Los pueblos originarios, los desplazados, la sociedad civil y la academia, han de emprender la lucha ecológica que se inicia a partir de la lucha cultural; la lucha científica desde los espacios académicos, la ciencia y las universidades, forman parte de este todo coherente y espacio propicio para el debate y la postulación de ideas.

Las comunidades indígenas y campesinas defendiendo los territorios y los recursos estratégicos y los políticos conscientes de que la ciencia no está aislada de la política como la mejor forma para ejercer la solidaridad, defender lo público por sobre lo privado, gestionar y administrar los recursos que son de todos. No obstante, es la lucha social de los indígenas y campesinos la que con más fuerza puede hablar y cambiar la realidad del medioambiente que está amenazado, pues son ellos los que más conocen en virtud de que están inmersos en ella y sufren directamente el drama de despojo y el desplazamiento.

Esta lucha tiene entre sus primeros retos, revisar las facilidades, exoneraciones y concesiones mineras a las transnacionales. El Estado no puede renunciar al deber de abogar por el bien común, el cual está vinculado a la formulación e impulso de políticas encaminadas a proteger la naturaleza y sus recursos, explotándolos de manera racional con el visto bueno y participación de las comunidades, para evitar la ejecución de proyectos a espalda de los pueblos que les atañe y que no tienen factibilidad económica, técnica y viabilidad política. Es tiempo de evitar seguir viendo los problemas de la sociedad y el mundo desde la óptica del mercado total, donde todo se mercantiliza.

El agua no es una simple mercancía en función solo del interés de unos pocos con visión cortoplacista, es un derecho, no un bien particular, no porque determinados grupos han contribuido a su agotamiento es que ahora se le tiene que poner precio con valor comercial que afectará aún más a los sectores vulnerables, porque despertará, como ya está sucediendo, el ansia de su acaparamiento. Pero, no porque algunos recursos se consideren como bienes comunes o derecho para las personas, como bienes gratuitos, es que deben derrocharse. Si la naturaleza es fuente de riqueza, también debemos tener conciencia que tienen limite, por ello hay que aprovechar- 
los racionalmente procurando su regeneración de manera sostenible, es decir: "Reproduciéndolos como reproducción de la vida... el sistema que sacrifica a los pobres, también sacrifica a la naturaleza, pese a que esta es la fuente de los recursos que alimentan su propia existencia. Para su sobrevivencia y constante expansión -crecimiento económico- requiere el uso cada vez más intensivo de recursos naturales... al no tomar como factor clave el medioambiente y las enseñanzas de la ecología, el sistema se autodestruye... Ser antiecológico es irracional, pues predice su propia muerte" (May, 2004).

En toda esta problemática del cambio climático no se puede dejar de abordar de manera específica el problema de los transgénicos y sus consecuencias nocivas para los seres vivos, por sus efectos dañinos en la salud de las personas, causándoles enfermedades de la piel e intoxicándolos de manera directa e indirecta por el consumo del agua contaminada. A estos daños tampoco escapan la flora y los animales. El crecimiento acelerado de la agricultura industrial, como parte de la nueva revolución industrial, no solo busca la comercialización rápida y convertir todo en mercancía para ponerlo a la venta, de manera que genere riqueza también en forma acelerada. Ello implica utilizar al máximo la tecnología de los agroquímicos, estos no solo afectan las áreas ocupadas por las transnacionales, principales responsables de esta práctica agrícola, desde luego que es obvio que también perjudican el entorno donde operan estas grandes empresas.

Como parte del fenómeno de la polinización que ocurre por efecto de las corrientes de aire, la movilidad de las abejas y otros insectos, los pajarillos y las corrientes que fluyen por toda la zona o región donde están las tierras colindantes con las tierras de las transnacionales, los frutos y semillas transgénicas dan una aparente resistencia a las plagas y enfermedades, se desarrollan más grandes, lo que desde el enfoque utilitarista genera más dinero, pero a costa de la salud de las personas y los animales. Los cultivos transgénicos no solo son dañinos a la salud de los seres humanos y los animales, también destruyen los suelos y contribuyen a la desaparición de las semillas originarias de los pueblos, como ya ha sucedido con algunas especies y variedades de maíz y otros cultivos de los países de Latinoamérica, especialmente en México.

Los agroquímicos no solo causan enfermedades a la gente y contaminan el agua, sino que también pueden arruinar y destruir las hojas de los árboles y todo el follaje de las áreas selváticas. De modo que los productos transgénicos no constituyen ninguna alternativa para proveerlos a los países pobres y terminar con el hambre de cerca de mil millones de personas en el mundo, porque sus efectos nocivos solo 
causan destrucción enfermedad y muerte.

Nadia Dem-boski es una agricultora brasileña y relata así su experiencia: "Queríamos producir leche ecológicamente, aquí en esta granja, leche sin productos tóxicos o químicos. Pero nuestro problema más grande fue demarcar el límite entre nosotros y las grandes empresas que fumigan y envenenan nuestra producción. Porque ese era el alimento de nuestros animales, así que la leche también estaba contaminada. Por eso no pudimos producir leche ecológica (Barrez, 2009 p. 76).

Son muchos los frutales y cultivos que se producen transgénicamente entre ellos la papa, la soya, el maíz; todo cultivo genéticamente modificado no puede ser más sano y limpio que el cultivo criollo natural. La contradicción estriba en que se lanzan campañas de propaganda en la que se dice que la agricultura será orientada a mantener el ambiente limpio de plagas y enfermedades, pero el resultado es a la inversa, se ensucia el medioambiente con gases tóxicos que constituyen un veneno para los seres humanos y animales. Hay que caer en cuenta que en este campo no se pueden establecer límites territoriales entre los que usan agroquímicos y los que no los usan, porque aquí juegan un papel importante el aire, las abejas, los pájaros, las corrientes de agua, etc. que transfieren las semillas, la polinización, los gases tóxicos de unos campos a otros; este fenómeno natural no establece límites territoriales, es parte de los ciclos naturales.

\section{RESULTADOS}

1. Las grandes empresas transnacionales son las principales responsables de la contaminación ambiental y del desplazamiento de grandes contingentes poblacionales, en virtud de la desarticulación que ha venido sufriendo la agricultura campesina e indígena como resultado de la primacía de la agricultura industrial de monocultivo, sobre la economía campesina y originaria.

2. La crisis ecológica como efecto del cambio climático es una manifestación de la crisis del modelo de acumulación, basado en el crecimiento y consumo desmedido sin guardar la racionalidad, en la explotación y el uso de los recursos.

3. Aprovechar los recursos naturales sin conciencia del límite, nos autodestruye en virtud de que dependemos de la naturaleza para sobrevivir y es de la naturaleza de donde se saca la materia prima que se necesita para elaborar los bienes 0 productos que el ser humano necesita en la satisfacción de necesidades.

4. La deforestación, los incendios forestales, la tala ilegal de árboles y el gorgojo 
descortezador, han venido a disminuir los ciclos pluviales, causando erosión de suelos, cambio en los ciclos productivos, secando las fuentes de agua y modificando los ciclos que regulan el clima. Todo lo cual incide en la pérdida de la biodiversidad zoológica y vegetal.

5. En el país más de 440 mil hectáreas las que han sido afectadas por el gorgojo descortezador en apenas siete meses, cifra que significa alrededor de 86 millones, 240 mil pinos, a un promedio de 196 pinos por hectáreas, según técnicos del ICF.

\section{CONCLUSIONES}

1. El crecimiento sin límite, el consumo desmedido y la explotación de los recursos naturales sin guardar la racionalidad, está poniendo en peligro el planeta y, por consiguiente, al mismo ser humano que depende de la naturaleza para la sobrevivencia.

2. Las medidas cortoplacistas del utilitarismo para la rentabilidad económica inmediata, sin importar las generaciones venideras, han dado pie para el acelerado agotamiento de las reservas naturales y la emisión de gases tóxicos de efecto invernadero, han resultado en un deterioro ambiental y disminución de la calidad de vida de la población.

3. La explotación irracional de la tierra, incluyendo la deforestación está relacionada con los patrones de apropiación de la propiedad, no es independiente del crecimiento desordenado de la población que presiona sobre un mismo espacio físico fijo y si no hay reordenamiento territorial genera conflictos agrarios.

4. El calentamiento global es una realidad y el agua que es o debe ser un derecho humano y un bien común, es cada vez más escaso, sin este preciado líquido no se puede vivir, de él dependemos los seres humanos y todo ser viviente, es componente vital de los procesos biológicos.

5. El afán de captar recursos y equilibrar balanza de pagos sobre la base de la explotación desmedida de los recursos naturales sin considerar los efectos ambientales y sociales, haciendo evaluaciones o valoraciones económicas de corto plazo, estimulando e impulsando la agricultura industrial para el mercado externo, desarticulando la agricultura indígena y campesina, poniendo así de este modo en riesgo la seguridad alimentaria y el desplazamiento de las comunidades originarias.

6. La lucha ecológica, la lucha cultural y científica de la academia como espacio propicio para la postulación de ideas y el debate en apoyo a la lucha social de los 
pueblos originarios y comunidades campesinas, como principales actores que están sufriendo directamente el drama del despojo y el desplazamiento, es uno de los principales retos para incidir en toda instancia que vaya encaminada a abogar por la reorientación de las políticas y programas económicos que se impulsan, conscientes de que el Estado no puede renunciar a su papel de trabajar por el bien común.

7. Es tiempo de tomar medidas urgentes para salvar el planeta, orientar la economía en función de la reproducción de la naturaleza para la reproducción de la vida es el reto principal insoslayable, del cual debemos ser partícipes todos los sectores.

\section{BIBLIOGRAFÍA}

Barrez, Dirk. (2009). Competencia a muerte: agricultura campesina versus agroindustria corporativa. Managua: Editorial Guaymuras y SIMAS, VECO MA.

Barros, Marcelo y Betto, Frei. (2011). El amor fecunda el universo. La Habana: Editorial de Ciencias Sociales.

Dierckxsens, Wim. (2009). La crisis mundial del siglo XXI: oportunidad de transición al poscapitalismo. Bolivia: DEI Editorial.

Departamento Ecuménico de Investigaciones. (2009). La gran depresión del siglo XXI: causas, carácter, perspectivas. DEI Editorial, Costa Rica.

Houtart, François. (2011). El escándalo de los agrocombustibles para el sur. Ecuador: Ruth Casa Editorial.

Houtart, François. (2012). De los bienes comunes al bien común de la humanidad. Panamá: Ruth Casa Editorial.

Hughes, William. (1998). Crecimiento y desarrollo: desarrollo sostenible. Memoria XI Congreso de Economistas de América Central y el Caribe. Tegucigalpa: Colegio Hondureño de Economistas.

Instituto de Conservación Forestal. (2016). Cálculos en base a datos del ICF. Honduras.

May, Roy H. (2004). Ética y medioambiente: hacia una vida sostenible. Costa Rica: Editorial Departamento Ecuménico de Investigaciones.

Papa Francisco. (2015). Laudato si: sobre el cuidado de la casa común. Carta Encíclica. Ciudad del Vaticano, Etrice Vaticana, Ediciones San Pablo.

Serrano, Augusto. (2003). Matriz teórica del desarrollo humano sostenible. Revista Paraninfo, 23, pp 121-176, revista del Instituto de Ciencias del Hombre, Tegucigalpa, Honduras. 